\title{
Video-assisted Thoracic Surgery (VATS) for Lung Cancer
}

\author{
Shizuka Kaseda, M.D., ${ }^{*}$ Teruhiro Aoki, M.D., ${ }^{*}$ Nanae Hangai, M.D., ${ }^{*}$ \\ and Kunihiko Shimizu, M.D.** \\ Departments of *Thoracic Surgery and **Internal Medicine, \\ Saiseikai Kanagawa-ken Hospital, Yokohama
}

From September 1992 to April 1999, 165 video-assisted thoracic surgery (VATS) lobectomies were performed at Saiseikai Kanagawa-ken Hospital. The lesions consisted of 130 cases of lung cancer, 12 cases of bronchiectasis, 8 cases of granuloma, 5 cases of metastatic tumors, and 10 cases with other miscellaneous diseases. Among the 130 cases with lung cancer, 94, who were diagnosed as stage I clinically, underwent a VATS lobectomy with extended lymph node dissection. The 5-year survival rate of these final stage I lung cancers following VATS was $96.6 \%$. This survival rate is significantly better than that for open thoracotomy $(78.5 \%: p<0.001)$. We conclude that VATS lobectomy with extended lymph node dissection can become a new standard procedure for clinical stage I lung cancer to replace open thoracotomy.

Key words : lung cancer, VATS, lobectomy, major lung resection, lymph nodes

Although thoracoscopy was initially introduced mainly as a diagnostic tool in the early 1900s, its clinical application started to gain widespread favor at the beginning of the 1990s. The associated techniques and instrumentation have accordingly developed rapidly. ${ }^{1-4)}$

Our first experience with video-assisted thoracic surgery (VATS) lobectomy was in September 1992, and we have since performed a total of 165 VATS lobectomies as of April 1999.

Furthermore, since November 1993 we have additionally applied VATS to extended lymph node dissection in lung cancer

Address reprints to Shizuka Kaseda, M.D. : Saiseikai Kanagawa-ken Hospital, 6-6 Tomiya-cho, Kanagawa-ku, Yokohama, Japan 221-0861 Received : May 18, 1999 patients. ${ }^{5,6)}$ We report on our techniques and results with VATS lobectomy, focusing on extended lymph node dissection for lung cancer.

\section{MATERIALS}

From September 1992 through April 1999, we performed 165 VATS major lung resections: 11 segmentectomies, 150 lobectomies and 4 pneumonectomies. The patients were 100 males and 65 females with an average age of 64 years (range: 28 to 87). The patients consisted of 130 cases with lung cancer, 12 with bronchiectasis, 8 with granulomas, 5 with metastatic tumors, and 10 with miscellaneous diseases. ${ }^{7)}$ Among the patients with lung cancer, the tumor size ranged from 11 to $67 \mathrm{~mm}$ (average : $34 \mathrm{~mm}$ ). The final histology 


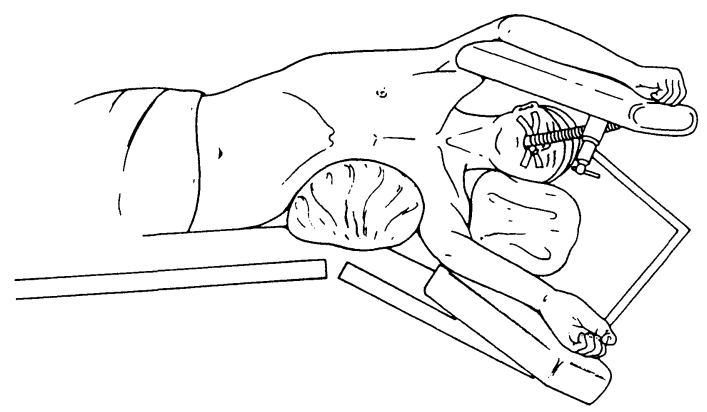

Fig. 1 Full flexion of the operating table, which naturally assists in the gradual opening of the intercostal space (Reprinted with permission, Ref. 6).

included 80 adenocarcinomas, 38 squamous cell carcinomas, and 12 other histological types. CT scans revealed no lymph node swelling larger than $1.5 \mathrm{~cm}$ in size in 110 patients, who were classified as N0 (stage I) preoperatively. Of these, 94 patients aged less than 75 years and without any major complications underwent our extended lymph node dissection.

\section{ANESTHESIA AND APPROACH}

After intubation with a double-lumened endotracheal tube (Broncho-Cath: MALLINCKRODT MEDICAL, USA) or an endobronchial tube with movable blocker for one lung anesthesia (UNIVENT ${ }^{\circledR}$ : Fuji Medical, Japan), the patient was fully flexed in the lateral decubitus position (Fig. 1).

The first incision was made in the seventh intercostal space at the mid-axillary line, and a thoracoscope was introduced through this opening. An anterolateral mini-thoracotomy $(5-8 \mathrm{~cm})$ was placed in the fourth intercostal space for an upper lobectomy or pneumonectomy, and in the fifth intercostal space for a middle or lower lobectomy. The extent of the incision was determined based on the size of the tumor or the volume of lung tissue which was to be removed. One or two 5-10 mm incisions were made additionally at the postero-axillary line (Fig. 2) to handle a variety of instruments.

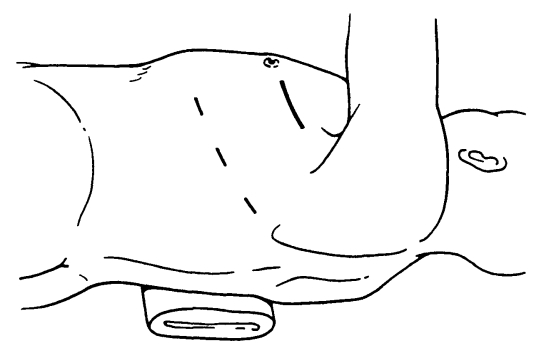

Fig. 2 Positions of access thoracotomy and additional incisions to facilitate lymph node dissection, as well as lobectomy (Reprinted with permission, Ref. 6).

\section{SURGICAL TECHNIQUE}

\section{Segmentectomy}

The pulmonary arteries were ligated with silk threads, using a forceps of the author's own invention, ${ }^{8)}$ and cut. The pulmonary artery was then taped and retracted to allow a better view of the bronchus. The bronchus was retracted with silk thread and then cut using an endostapler: ENDO GIA (United States Surgical Corporation: USCC, USA); or an ENDOCUTTER (ETS-FLEX or ETS45 : ETHICON-ENDOSURGERY, USA) (Fig. 3).

Following the transection of the pulmonary vein, the segmental fissure was also divided with endostaplers, and Dexon ${ }^{\mathrm{TM}}$ mesh (Davis \& Geck, Inc., USA) soaked in fibrin glue (Beriplast ${ }^{\circledR}$, Behringwerke AG, Germany) $)^{9}$ or gelatin resorcinol formaldehyde (GRF) glue (Cardial, France) was applied to the site to prevent air leakage.

\section{Lobectomy}

Small branches of the blood the vessels were ligated with silk threads and cut, but where the diameter of the pulmonary arteries and veins exceeded $10 \mathrm{~mm}$, they were transected with a vascular endostapler.

The bronchus was closed with a Roticulator 30-3.5 stapler (USSC) and transected with a scalpel in the first 100 cases. $^{5,6)}$ 


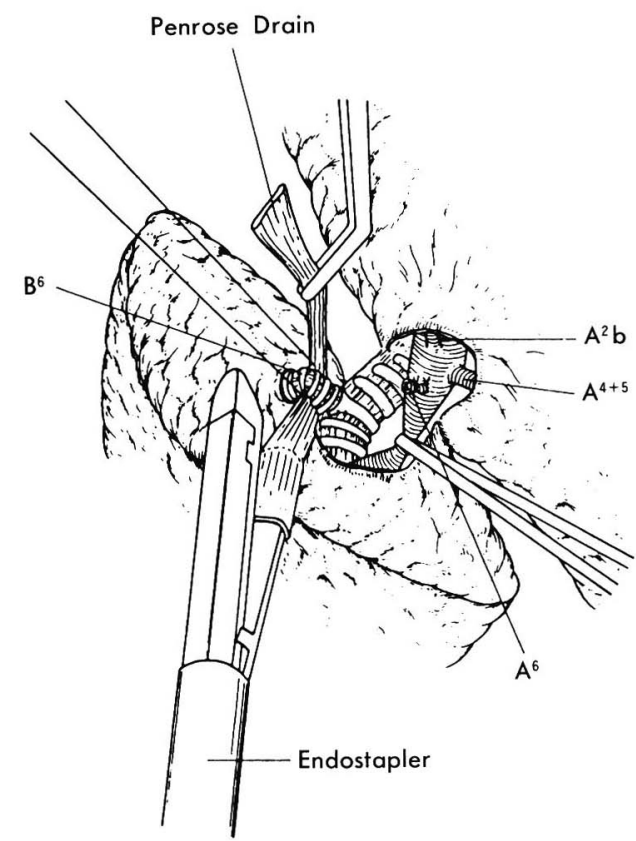

Fig. 3 Right $\mathrm{S}^{6}$ segmentectomy : Traction of the pulmonary artery with a tape, and transection of the $\mathrm{B}^{6}$ bronchus with an endostapler (Reprinted with permission, Ref. 6).

However, it was subsequently transected with an endostapler simply to reduce the cost of the procedure.

In 3 patients with massive adhesions between the pulmonary artery and the bronchus, the artery was stapled together with the bronchus by double stapling with Roticulator 30-3.5 staplers, and then transected in the distal portion according to Lewis's method. ${ }^{10)}$

The lobes were placed in a tough and elastic entrapment sac (LAPSAC: Cook Urological, USA), ${ }^{11)}$ and removed through the mini-thoracotomy.

\section{Pneumonectomy}

Of the 4 patients undergoing pneumonectomies, the pulmonary artery in the first patient was stapled using an ENDO GIA with its knife blade removed, and then cut in the middle of 6 rows of staples. In the second patient, a vascular clamp was placed at the distal portion of the 6 rows of staples, and the artery was cut between the staples

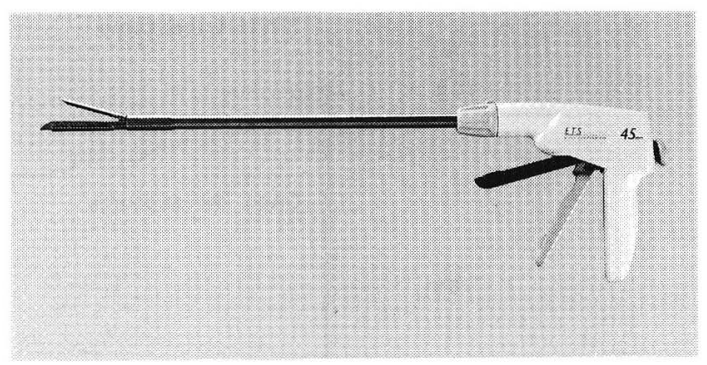

Fig. 4 Endocutter (ETS45)

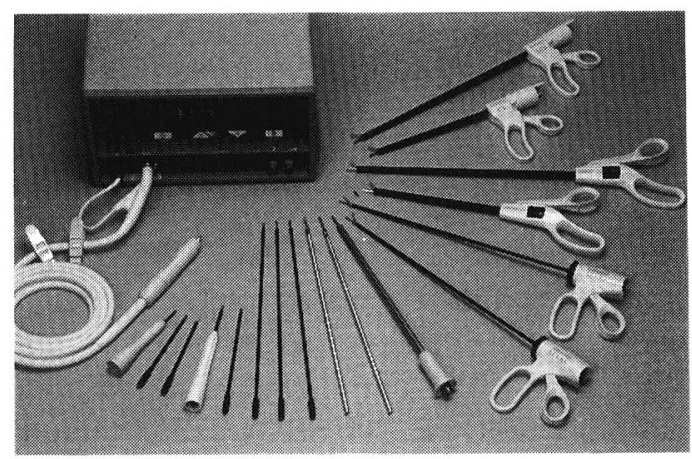

Fig. 5 Harmonic scalpel.

and the vascular clamp. In the remaining 2 patients, the main pulmonary artery was ligated with silk thread at the proximal portion for safety and then transected with ETS-FLEX or ETS45 (Fig. 4).

The main bronchus was transected after application of the Roticulator 30-4.8 stapler near the carina in all four patients.

\section{Lymph Node Dissection}

During lymph node dissection in the carinal region, the esophagus was compressed with an especially made spatula introduced through a $10 \mathrm{~mm}$ opening. The main bronchus was taped and pulled laterally, and the bronchial arteries were either clipped with endoscopic clips (ENDO CLIP II : USSC) and cut, or transected with electrocautery and the HARMONIC SCALPEL ${ }^{12}$ (ETHICON ENDOSURGERY) (Fig. 5).

During dissection in the upper mediastinum on the right side, the azygos vein was ligated with silk thread and transected. To obtain a 


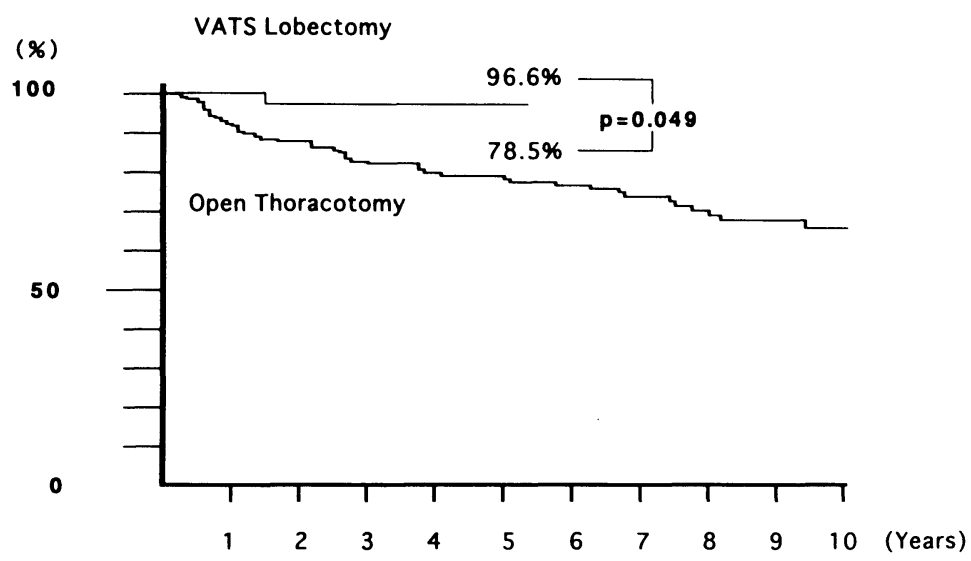

Fig. 6 Survival in final stage I lung cancer patients who have undergone VATS lobectomy and open thoracotomy.

better operative view, the silk thread attached to the vein was retracted laterally, while the vagus nerve was retracted with a silk thread pulled out of the thorax with an ENDO CLOSE (USSC). We used electrocautery or the HARMONIC SCALPEL in the extended resection of the upper mediastinal lymph nodes. Endoscopic clips were also frequently used to ligate small vessels during the lymph node dissection. When dissecting lymph nodes in the uppermost mediastinum, we did not use electrocautery to avoid damage to the recurrent laryngeal nerve.

The aortic arch was retracted with an ENDO RETRACT MAXI (USSC) or vascular tape on the left side, before the pretracheal and tracheobronchial lymph nodes were excised.

\section{RESULTS}

Early on in this series of operations, in one patient undergoing a right middle lobe lobectomy, the staples inserted with a vascular endostapler failed to close, and massive bleeding occurred from the pulmonary artery. However, the bleeding was promptly controlled by clamping the stump of the pulmonary artery and suturing it. Later, we made it a rule to apply vascular endostaplers to vessels with its knife blade removed and then cut, or to ligate vessels at their proximal portion and then apply endostaplers. ${ }^{5,6)}$

A severe asthmatic attack and pyothorax occurred in two patients; however, these complications were not fatal. One patient with emphysema and poor pulmonary function developed pneumonia due to MRSA after a right upper lobectomy and died of respiratory insufficiency six weeks after his operation (series mortality : $0.6 \%$ ). There were no other serious complications noted postoperatively.

The number of lymph nodes was 7 to 58 (average 23) in the 94 patients who underwent the extended lymph node dissection under our diagnosis of clinical stage I lung cancer. Of these 94 patients, pathological examination revealed $\mathrm{N} 0$ in 57 patients, $\mathrm{N} 1$ in 8 and $\mathrm{N} 2$ in 29. Patients with $\mathrm{N} 0$ and $\mathrm{N} 1$ were discharged on the 10th to 14 th postoperative day after confirming the absence of bronchial fistula by bronchoscopy. However, patients classified as $\mathrm{N} 2$ received one or two cycles of chemotherapy with cis-platin, vindesine, mitomicin and CPT-11.

Of the $57 \mathrm{~N} 0$ (pathological stage I patients), one developed generalized bone metastasis and died 20 months after an operation. However, no recurrence has been noted in the remaining patients during 1 to 66-month follow-up (median : 27 months), and the 5-year 
survival rate for the pathological stage I cancer cases was $96.6 \%$. This survival rate was far better than that of patients undergoing open thoracotomy between 1976 and 1990 (78.5\%: $p<0.001$ ) (Fig. 6).

\section{CONCLUSIONS}

Soon after the introduction of the thoracoscopic technique, we started VATS lobectomies in 1992. ${ }^{5,6)}$ Since the instrumentation for thoracoscopic surgery is expensive and not necessarily adequate for performing major lung resections such as lobectomies, we have been using conventional thoracic surgical instruments and ligating small blood vessels with silk threads using a pair of forceps of the author's own invention ${ }^{8)}$ to reduce costs. However, in cases where the diameter of the vessels is large, we have no option but to use endostaplers.

When we began doing VATS lobectomies, the only reliable endostapler was the ENDO GIA. The ENDO GIA clasps the tissue with 6 rows of staples and simultaneously transects between the staple rows with a knife-blade. However, in our early experience, a massive hemorrhage occurred from the pulmonary artery because the artery had been cut with the knife-blade when the staples failed to close properly. In this case, the pulmonary artery was luckily clamped with a vascular clamp and successfully sutured.

It is very rare for an endostapler to staple vessels insufficiently, ${ }^{13)}$ but once it happens, it is life-threatening. Therefore, we made it a rule to staple a vessel with a vascular ENDO GIA after removing its knife blade and then cut the vessel. When using an endostapler whose blade can not be removed, it was used only after ligating the proximal portion of the vessels for safety. Since this alteration in our technique, we have not encountered any major complications from bleeding.

Concomitant with the improvement in techniques and instrumentation thereafter, we started performing VATS lymph node dissec- tions on November 1993. In the present series, 7 to 58 (average: 23) lymph nodes were resected by VATS. This number was comparable to conventional open thoracotomy. Although we think it questionable whether or not extended lymph node dissection can improve prognosis, ${ }^{14-17)}$ radical resection of the lymph nodes provides accurate staging and a dependable information for prognosis.

Furthermore, the 5-year survival rate following VATS lobectomy combined with extended lymph node dissection for pathological stage I cancer was $96.6 \%$ (Fig. 6), which is far better than that of open thoracotomy (78.5\%: $p<0.001)$.

It is believed that metastases occur most commonly during the intra-perioperative period, when injury and repair are most prominent and stress can elaborate various humoral substances which potentiate the growth of carcinomas. ${ }^{18)}$ Thus, Lewis proposed that a minimally invasive surgery with the small incisions required for VATS could account for the improved long-term survival after VATS lobectomy by providing a less favorable environment for malignant cell growth. Furthermore, in VATS fewer malignant cells are disseminated and passed into the blood vessels or lymphatics, which could occur from the extensive mechanical stress through palpation and compression common to the open technique. ${ }^{19)}$

It is clear that VATS lobectomy with lymph node dissection has already gone well beyond the stage of an experimental technique, and is on the way to becoming a standard procedure for stage I lung cancer.

\section{REFERENCES}

1) Lewis, R.J., Caccavale, R.J., Sisler, G.E., et al. : One hundred consecutive patients undergoing video-assisted thoracic operations. Ann. Thorac. Surg., 54:421-426, 1992.

2 ) Roviaro, G.C., Rebuffat, C., Varoli, F., et al. : Videoendoscopic thoracic surgery. Int. Surg., $78: 4-9,1993$. 
3 ) Kirby, T.J., and Rice, T.W. : Thoracoscopic lobectomy. Ann. Thorac. Surg., 56:784-786, 1993.

4) DeCamp, M.M., Jacklitsch, M.T., Mentzer, S.J., et al.: The safety and versatility of video-thoracoscopy: A prospective analysis of 895 consecutive cases. J. Am. Coll. Surg., $181: 113-120,1995$.

5 ) Kaseda, S., Hangai, N., Yamamoto, S., et al. : Lobectomy with extended lymph node dissection by video-assisted thoracic surgery for lung cancer. Surg. Endosc., 11:703-706, 1997.

6 ) Kaseda, S., Aoki, T., and Hangai, N. : Videoassisted thoracic surgery (VATS) lobectomy : The Japanese experience. Semin. Thorac. Cardiovasc. Surg., $10:$ 300-304, 1998.

7 ) Kaseda, S., Aoki, T., Hangai, N., et al. : A case of deep laceration of the lung treated with video-assisted thoracic surgical lobectomy : Case report. J. Trauma, $43: 856^{-}$ 858, 1997.

8 ) Kaseda, S. : Inventor. FORCEPS. US patent 5,792,177. Aug. 11, 1998.

9 ) Kaseda, S., Aoki, T., Hangai, N., et al. : Treating bullous lung disease with Holmium YAG laser in conjunction with fibrin glue and DEXON $^{\mathrm{TM}}$ mesh. Laser Surg. Med., 22 : 219-222, 1998.

10) Lewis, R.J. : Simultaneously stapled lobectomy: A safe technique for videoassisted thoracic surgery. J. Thorac. Cardiovasc. Surg., $109:$ 619-625, 1995.

11) Clayman, R.V., Kavoussi, L.R., Soper, N.J., et al. : Laparoscopic nephrectomy: Review of the initial 10 cases. J. Endourol., 6:127-132,
1992.

12) Aoki, T., and Kaseda, S.: Thoracoscopic resection of the lung with the ultrasonic scalpel. Ann. Thorac. Surg., 67:1181-1183, 1999.

13) Yim, A.P.C., and Ho, J.K.S. : Malfunctioning of vascular staple cutter during thoracoscopy lobectomy. J. Thorac. Cardiovasc. Surg., $109: 1252,1995$.

14) Daly, B.D.T., Mueller, J.D., Faling, L.J., et al. : N2 lung cancer: Outcome in patients with false-negative computed tomographic scans of the chest. J. Thorac. Cardiovasc. Surg., $105:$ 904-911, 1993.

15) Naruke, T., Goya, T., Tsuchiya, R., et al. : The importance of surgery to non-small cell carcinoma of lung with mediastinal lymph node metastasis. Ann. Thorac. Surg., 46: 603-610, 1988.

16) Pearson, F.G. : Staging of mediastinum: Role of mediastinoscopy and computed tomography. Chest, $103: 346 \mathrm{~s}^{-348 s,} 1993$.

17) Shields, T.: The significance of ipsilateral mediastinal lymph node metastasis (N2 disease) in non-small cell carcinoma of the lung. A commentary. J. Thorac. Cardiovasc. Surg., 90:48-53, 1990.

18) Reid, S.E., Kaufman, M.W., Murthy, S., et al. : Perioperative stimulation of residual cancer cells promotes local and distant recurrence of breast cancer. J. Am. Coll. Surg., 185:290-306, 1997.

19) Lewis, R.J., and Caccavale, R.J. : Videoassisted thoracic surgical non-rib spreading simultaneously stapled lobectomy. Semin. Thorac. Cardiovasc. Surg., $10: 332-339$, 1998. 